\title{
Avaliação do desempenho ambiental de uma instituição pública de ensino técnico e superior
}

\author{
Thomaz Sessegolo Marques de Almeida ${ }^{a *}$, Miguel Afonso Sellitto \\ a*thomazparobe@bb.com.br, UERGS, Brasil \\ bsellitto@unisinos.br, UNISINOS, Brasil
}

\begin{abstract}
Resumo
0 objetivo deste artigo foi relatar um estudo de caso baseado em indicadores ambientais categóricos no qual foi avaliado o desempenho ambiental de uma instituição pública de ensino técnico e superior. A revisão incluiu a série de normas ISO 14000, o Prêmio Nacional de Qualidade em Saneamento (PNQS) e o Ecoblock. 0 método usado foi adaptado do SBP, um conjunto de procedimentos para a mensuração do desempenho ambiental de uma atividade antrópica, que se vale de construtos latentes e indicadores categóricos que expliquem o desempenho. Os indicadores foram organizados em sete construtos. Segundo os avaliadores e o modelo, a instituição faz 56,7\% do máximo possível em gestão ambiental. Os construtos mais carentes foram gestão de resíduos sólidos e poluição sonora. 0 resultado da avaliação pode ser usado para reformulação da política ambiental da instituição.
\end{abstract}

Palavras-chave

Desempenho ambiental. Métodos de avaliação. Indicadores ambientais.

\section{Introdução}

A partir dos anos 1960 e 1970, a preocupação com o meio ambiente tem sido pauta de encontros de chefes de estado e influenciado relações internacionais. Mais recentemente, empresas de classe mundial passaram a considerar gastos com proteção ambiental como sendo investimento e não como custo (CAMPOS; MELO, 2008). De maneira geral, nas últimas décadas do século XX, cientistas e praticantes se preocuparam mais com os impactos ambientais gerados pela atividade antrópica (MATIAS; PINHEIRO, 2008).

Crescimento econômico e preservação ambiental já foram considerados contraditórios: para alcançar um devia-se abrir mão do outro. Não era incomum a visão de que a proteção ambiental freava o crescimento econômico (ARAUJO; MACHADO, 2007). Problemas ambientais podem ser parcialmente atribuídos a processos industriais: todo produto ou processo provoca impacto no ambiente, tanto pelas matériasprimas como pelo uso de energia e o tipo de disposição final que exige (CHEHEBE, 1997). Hoje já há evidências suficientes que a industrialização, a expansão da fronteira agrícola e a urbanização criaram pressões significativas no patrimônio natural, devido à utilização de recursos naturais exauríveis e à degradação da qualidade ambiental (MOTTA, 1996). No entanto, crescimento econômico e preservação ambiental podem ser harmonizados por práticas ambientalmente amigáveis, inseridas na gestão ambiental (MICHELSEN; MAGERHOLM; DAHLSRUD, 2006).

Neste contexto, a Organização das Nações Unidas (ONU) criou em 1983 a Comissão Mundial sobre Meio Ambiente e Desenvolvimento, com o objetivo de discutir e propor meios de harmonizar economia e ambiente. A comissão definiu desenvolvimento sustentável como aquele capaz de suprir as necessidades da geração atual sem comprometer as necessidades das gerações futuras: o contínuo desenvolvimento da sociedade atual não deve esgotar ou comprometer os recursos naturais que serão herdados pelas futuras gerações (ORGANIZAÇÃO..., 2010). 
0 conceito de desenvolvimento sustentável surgiu formalmente no relatório da Comissão Mundial sobre Meio Ambiente e Desenvolvimento intitulado Nosso Futuro Comum, organizado sob a liderança de Gro Harlem Brundtland. 0 conceito envolveu o estado atual da tecnologia e a capacidade da biosfera de lidar com os efeitos das atividades humanas. Em sintese, desenvolvimento sustentável não é um estado de equilíbrio a ser alcançado, mas um processo de mudança no qual a exploração dos recursos, a orientação de investimento, o desenvolvimento tecnológico e as estruturas institucionais são concebidos para conciliar necessidades atuais e necessidades futuras (BRUNDTLAND, 1987). 0 conceito desenvolvimento sustentável modifica os esforços desenvolvimentistas com significativas implicações econômicas e políticas para o mundo atual (MOTTA, 1997), fazendo convergir interesses políticos, científicos e da sociedade em geral, como caminho alternativo à crise ambiental e ao aumento de consciência crítica (MATIAS; PINHEIRO, 2008). 0 desenvolvimento sustentável é baseado em três aspectos: desempenho ambiental, responsabilidade social e contribuição econômica (KRAJNC; GLAVIC, 2005). Este artigo preocupou-se com o primeiro.

No contexto do desenvolvimento sustentável, vale destacar iniciativas como a exigência de estudos de impactos ambientais para obras financiadas pelo Banco Mundial, a crescente conscientização de consumidores, o surgimento de ONGs, a adoção de sistemas de gestão ambiental (SGAs) (PIMENTA; GOUVINHAS, 2007), o desenvolvimento de produtos com elevado desempenho ambiental (WAAGE, 2007) e a instalação de tecnologia ambiental do tipo zero impacto ou zero emissão (KUEHR, 2007). Também vale destacar o novo papel que se espera da tecnologia de produção: gerar menos resíduos e consumir menos recursos naturais, principalmente os não renováveis (BARBIERI, 2004).

Como consumidores conscientes consideram mais do que preço e qualidade na decisão de compra, evidenciar a gestão ambiental praticada pode agregar valor para organizações e partes interessadas (BORGES; ROSA; ENNSLIN, 2010). A gestão dos ativos naturais tornou-se função estratégica, exigindo políticas, metas, planos de ação e métodos para mensuração de uma grandeza intangível mas decisiva nesse novo cenário, o desempenho ambiental (ARAUJO; MACHADO, 2007). Zobel et al. (2002) definiram desempenho ambiental como a informação analítica oferecida por múltiplos indicadores organizados segundo um sistema de mensuração. A contínua mensuração do desempenho ambiental permite direcionar ações segundo metas e objetivos ambientais prioritários (JOHNSON, 1998) e melhorar os resultados da gestão ambiental (KUHRE, 1998).
O objetivo geral deste artigo foi avaliar o desempenho ambiental de uma instituição pública de ensino que oferece cursos técnicos e sedia cursos superiores. Os objetivos específicos foram: definir os construtos latentes e seus respectivos indicadores, mensurá-los e usar a mensuração para priorização de ações ambientais. 0 método de pesquisa foi a modelagem numérica qualitativa, pois o modelo matemático se originou de opiniões e impressões de especialistas organizadas em formato numérico. A instituição foi constituída há mais de 40 anos, em área com 20 ha de vegetação nativa, acolhendo hoje muito mais alunos e atividades do que quando projetada, demandando mais recursos naturais e gerando mais rejeitos do que então. 0 método de pesquisa foi adaptado a partir do método SBP (iniciais dos autores), originalmente aplicado em operações industriais (SELLITTO; BORCHARDT; PEREIRA, 2008, 2009, 2010). 0 método se baseia em percepções de especialistas em gestão ambiental com conhecimento do objeto em avaliação.

\section{Gestão ambiental e sistemas de gestão ambiental (SGAs)}

A necessidade do gerenciamento ambiental foi percebida já nos anos 1960, quando se verificou que as capacidades assimilativa dos ecossistemas e de regeneração dos recursos naturais ocorriam a taxas incompatíveis com o desgaste imposto pelos meios produtivos (BARATA; KLIGERMAN; MINAYO-GOMEZ, 2007). Pressões internacionais têm sido exercidas no sentido da preservação do patrimônio natural e de maior controle de atividades industriais. Tal pressão se materializa nas restrições impostas pelo mercado internacional a empresas de baixo desempenho ambiental (REIS, 1995). No Brasil, a gestão ambiental tem se valido da regulação, ou seja, do uso de instrumentos oficiais de controle. Na Política Nacional do Meio Ambiente há quatro classes de instrumentos: (i) padronização das emissões ambientais; (ii) controle do uso do solo; (iii) licenciamentos e estudos de impacto ambiental (EIA/Rima); e (iv) legislação penalizadora. Na Constituição de 1988, biomas como Amazônia e Pantanal foram declarados patrimônio nacional e criadas leis específicas para sua proteção (MOTTA, 1996).

Em atividades industriais, empresas têm sido avaliadas não apenas pelo desempenho ou qualidade de seus produtos e serviços, mas também por sua responsabilidade social e ambiental (WALKER; DI SISTO, McBAIN, 2008). A imagem das empresas tem sido associada ao impacto que suas operações causam. Ao incorporar a preservação ambiental aos seus compromissos de gestão, a empresa pode melhorar 
sua imagem corporativa e eventualmente aumentar seus negócios em mercados mais maduros (OTTMAN, 1994). Com isto, gestores têm adotado atitudes e posturas não mais defensivas e reativas, mas ativas e criativas, adaptadas a essa nova visão estratégica (CAMPOS; MELO, 2008), tratando a gestão ambiental como instrumento estratégico capaz de construir vantagem competitiva (ADLMAIER; SELLITTO, 2007).

Conforme Epelbaum (2004), a gestão ambiental pode ser entendida como a parte da gestão empresarial que zela pela identificação, avaliação, controle, monitoramento e redução dos impactos ambientais a níveis pré-definidos. Nesse contexto, algumas definições da norma ISO 14001 podem ser destacadas (ASSOCIAÇÃO..., 1996): (i) aspecto ambiental: elemento das atividades, produtos ou serviços de uma organização que pode interagir com o meio ambiente; (ii) impacto ambiental; modificações do meio ambiente resultantes, no todo ou em parte, de atividades, produtos ou serviços de uma organização; (iii) sistema de gestão ambiental: parte do sistema de gestão que inclui estrutura organizacional, planejamento, responsabilidade, práticas, procedimentos, processos e recursos para desenvolver, implementar, atingir, analisar criticamente e manter a política ambiental; (iv) desempenho ambiental: resultado mensurável do sistema de gestão ambiental, relativos ao controle da organização sobre seus aspectos ambientais, com base na sua política, objetivos e metas ambientais; e (v) política ambiental: declaração da organização expondo intenções e princípios em relação ao desempenho ambiental global, o que provê uma estrutura para ação e definição de objetivos e metas ambientais. Epelbaum (2004) aponta alguns dos principais impactos e aspectos relevantes para análise, expostos no Quadro 1.

Um elemento relevante em gestão ambiental são os SGA (sistemas de gestão ambiental), responsáveis por gerenciar o impacto das atividades produtivas no ambiente. SGAs podem fazer parte de sistemas integrados de gestão, incluindo qualidade, saúde e segurança do trabalho e responsabilidade social (GRAEL; OLIVEIRA, 2010). Um SGA pode apoiar empresas no controle e redução permanente de impactos ambientais (ROWLAND-JONES et al., 2005). SGAs incluem políticas, procedimentos e protocolos de auditoria aplicáveis a operações empresariais (MATTHEWS, 2003). Por seu caráter estratégico, o SGA atende objetivos ambientais e também econômicos por: (i) diminuição de desperdícios e rejeitos; (ii) adequação dos produtos e processos de produção às necessidades do mercado; e (iii) troca de equipamentos por outros mais eficientes em consumo energético e menos interferentes na natureza. SGAs formalizam procedimentos operacionais e incentivam a melhoria contínua, possibilitando a redução de resíduos e do consumo de recursos naturais. SGAs são importantes alternativas para a compatibilização de fatores ambientais e econômicos (OLIVEIRA; PINHEIRO, 2010). 0 SGA exige estabelecimento de metas e controle do nível de desempenho ambiental, cobrindo todo o ciclo de vida do produto, desde a concepção até o descarte ou reaproveitamento (VALLE, 1995).

Quadro 1. Principais aspectos e impactos ambientais.

\begin{tabular}{|c|c|c|}
\hline Tema & Aspecto ambiental & Impacto ambiental primário \\
\hline \multirow{7}{*}{$\mathrm{Ar}$} & \multirow{5}{*}{ Emissão atmosférica } & Poluição do ar \\
\hline & & Contribuição à chuva ácida \\
\hline & & Redução da camada de ozônio \\
\hline & & Contribuição ao efeito estufa \\
\hline & & Formação de smog fotoquímico \\
\hline & Ruído & Incômodo à comunidade \\
\hline & Radiação & Contaminação radioativa \\
\hline \multirow{3}{*}{ Solo } & Movimentação de terra & Erosão \\
\hline & Resíduos sólidos & Poluição do solo \\
\hline & & Poluição da água \\
\hline \multirow[t]{2}{*}{ Água } & Efluentes & Acidificação \\
\hline & & Eutrofização \\
\hline Flora & Desmatamento & Supressão da vegetação \\
\hline \multirow{2}{*}{ Fauna } & Movimentação de equipamentos & Perturbação/evasão de fauna \\
\hline & Efluente líquido & Ecotoxicidade \\
\hline \multirow{4}{*}{ Sociedade } & \multirow{4}{*}{ Atividades do empreendimento } & Geração de empregos \\
\hline & & Geração de tributos \\
\hline & & Dinamização da economia regional \\
\hline & & Uso do solo \\
\hline cursos naturais & Extração dos recursos naturais & Exaustão dos recursos naturais \\
\hline
\end{tabular}


Um modo de garantir o resultado do SGA é a monitoração contínua de um conjunto de indicadores de desempenho ambiental (CAMPOS; MELO, 2008). Dos inúmeros modelos de controle de desempenho já propostos, alguns foram mais úteis nesta pesquisa: as normas da série 1SO 14000 , pela aceitação internacional; o PNQS, por contemplar relevante setor para o desenvolvimento socioambiental; o Ecoblock, por tratar de cadeias produtivas; e o SBP, por permitir flexibilidade nos indicadores.

\subsection{As normas da série ISO 14000}

A série 1SO 14000 integra 28 normas abrangendo seis áreas: sistema de gestão ambiental; auditorias ambientais; avaliação de desempenho ambiental; rotulagem ambiental; aspectos ambientais nas normas de produtos; e análise do ciclo de vida do produto (CAMPOS; MELO, 2008). A série colocou a gestão ambiental no mesmo plano da gestão da qualidade, criando mais um condicionante para empresas que concorrem no mercado globalizado. Conciliar as características ambientais dos produtos com princípios ambientalmente amigáveis tornou-se requisito essencial para empresas exportadoras. Como a série ISO 14000 não é obrigatória, diferencia-se dos dispositivos oficiais de regulação: a velocidade das certificações é ditada pela pressão dos mercados (SOUZA; SILVA, 1997).

As normas ISO 14000 foram formuladas pela International Organization for Standardization (ISO) em 1996 e desde então têm sido difundidas pelo mundo. Organizações voluntariamente as têm adotado, certificadas por organismos credenciados (ÁVILA; PAIVA, 2006). Tais organismos orientam as organizações na implantação e manutenção de políticas ambientais que considerem as condições legais e as informações acerca dos impactos ambientais (SEIFFERT, 2007; DONAIRE, 1999).

As normas ISO 14001 formam um dos modelos de gestão ambiental mais implantados no mundo. Uma característica das normas é a padronização de rotinas e procedimentos, segundo um roteiro válido internacionalmente. A norma não se contrapõe à legislação local vigente, mas a fortalece, pois exige total cumprimento para a certificação (VALLE, 2002). A norma ISO 14001:2004 é organizada em: introdução; objetivo; referências normativas; termos e definições; requisitos do sistema de gestão ambiental (requisitos gerais, política ambiental, planejamento, implantação e operação, verificação e ação corretiva e análise crítica pela administração) e orientações para o uso da norma (OLIVEIRA; PINHEIRO, 2010). A série oferece uma estrutura formal de gerenciamento (Figura 1), cujo objetivo é aumentar continuamente o desempenho ambiental de uma organização (DONNELLY et al., 2004).

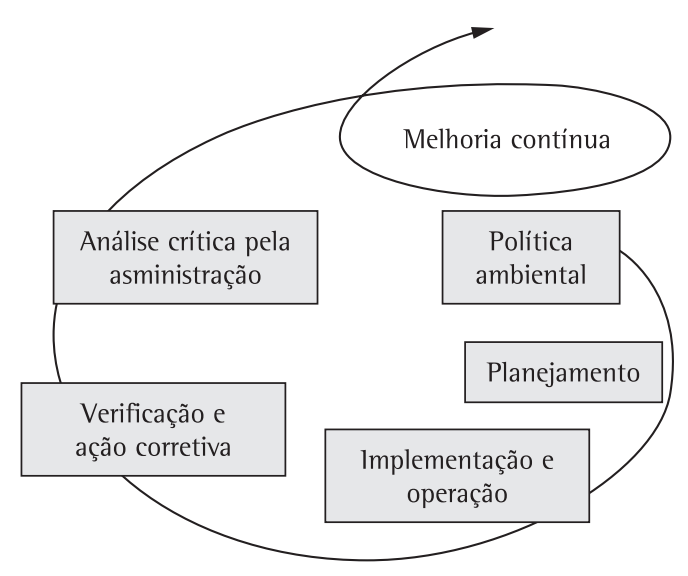

Figura 1. Espiral do sistema de gestão ambiental. Fonte: Oliveira e Pinheiro (2010).

Por fim, cabe destacar que os princípios de uma das normas da família, a ISO 14031, têm subsidiado modelos para avaliação de desempenho ambiental baseado em indicadores ambientais gerenciais e operacionais (CAMPOS; MELO, 2008).

\subsection{Ecoblock}

0 Ecoblock é um método de avaliação de desempenho ambiental desenvolvido para calcular pressões ambientais com base em indicadores. Pressões ambientais são fatores de produção que configuram consumo de recursos naturais ou representam potencial de degradação ambiental. A avaliação usa indicadores cumulativos, aplicáveis ao longo de territórios, cadeias produtivas ou indústrias inteiras. Os indicadores refletem as pressões ambientais das atividades que compõem a cadeia ou território, permitindo comparações entre setores e identificando criticidades ao longo deles (MELO; PEGADO, 2002).

0 Quadro 2 mostra os indicadores e os respectivos critérios de cálculo utilizados no Ecoblock. Os indicadores: (i) são aditivos, podendo ser acumulados ao longo da cadeia produtiva; (ii) são flexíveis, podendo avaliar o desempenho em vários tipos de atividade; (iii) representam pressões ambientais, ou seja, pressões exercidas sobre o ambiente, mas não o estado quiescente do ambiente; e (iv) estão correlacionados com impactos regionais, nacionais ou globais (PEGADO; MELO, RAMOS, 2001). 0 método usa apenas indicadores operacionais, desconsiderando indicadores gerenciais (VERDUM; SELLITTO, 2009).

\subsection{Prêmio Nacional de Qualidade em Saneamento}

0 Prêmio Nacional de Qualidade em Saneamento (PNQS) é promovido pela Associação Brasileira de 
Quadro 2. Sistema de indicadores e respectivos critérios de cálculo.

\begin{tabular}{cc}
\hline Indicadores & Critérios para o cálculo dos indicadores \\
\hline Consumo de água & Proveniência e renovabilidade da origem da água \\
Potencial de aquecimento global & Emissões associadas à produção e consumo de energia \\
Emissões poluentes (sólidas, líquidas, gasosas) & Outras emissões de gases do efeito estufa \\
Consumo de materiais & Periculosidade equivalente \\
Ocupação de área & Renovabilidade das fontes \\
\hline
\end{tabular}

Fonte: Pegado, Melo e Ramos (2001).

Engenharia Sanitária e Ambiental (ABES). Seu objetivo é estimular a prática de modelos gerenciais compatíveis com os melhores exemplos mundiais, pela promoção e reconhecimento de casos de sucesso que auxiliem no aprimoramento do setor e no aumento da qualidade de vida da população. Além disso, o PNQS surgiu para: (i) estimular a busca e aplicação de boas práticas de gestão nas empresas de saneamento; (ii) reconhecer aquelas que se destacarem pela utilização das práticas e pelo desempenho; (iii) divulgar as práticas reconhecidas em seminários e publicações de casos finalistas e vencedores; e (iv) promover eventos de capacitação gerencial (PRÊMIO..., 2008).

$\mathrm{Na}$ avaliação são envolvidos os processos referentes ou associados a três setores: (i) captação de água; (ii) tratamento e distribuição de água e coleta, tratamento e disposição final dos esgotos sanitários; e (iii) coleta, processamento e disposição final de resíduos sólidos e drenagem urbana. As premiações são divididas em quatro categorias: níveis l, 11,111 e IV. Nas três primeiras é avaliado o sistema de gestão completo da organização candidata. Na última, denominada de Inovação da Gestão em Saneamento (IGS), são avaliadas práticas de gestão específicas introduzidas nos últimos cinco anos (PRÊM1O..., 2008).

Os critérios de avaliação dos três primeiros níveis examinam o grau de maturidade na implementação dos fundamentos da excelência pelas organizações do setor de saneamento. Isso possibilita a avaliação dos processos gerencias e dos resultados organizacionais. Os fundamentos de excelência são incorporados no modelo de gestão por 11 princípios: pensamento sistêmico; aprendizado organizacional; cultura de inovação; liderança e constância de propósitos; orientação por processos e informações; visão de futuro; geração de valor; valorização das pessoas; conhecimento sobre o cliente e o mercado; desenvolvimento de parcerias; e responsabilidade. A excelência na gestão é mensurada por meio de oito critérios: liderança; estratégia e planos; clientes; sociedade; informação e conhecimento; pessoas; processos; e resultados (PRÊM10..., 2008).

No nível IV (IGS), a avaliação é feita por critérios, itens e fatores. São quatro critérios: oportunidade, ideia, resultados e apresentação pública. Dentro dos critérios existem oito itens de avaliação. Cada item é avaliado em fatores. Os critérios desse nível apresentam relação com os níveis 1,11 e 111 pois, para ser elegível, o caso proposto deve estar relacionado com métodos de gestão exigidos em um ou mais aspectos dos critérios. 0 projeto deve apresentar elementos clássicos da gestão de classe mundial, tais como padronização, controle, aprendizado e demonstração de eficácia por resultados. Esses elementos garantem a repetição do processo gerencial dentro de padrões de conformidade e a melhoria contínua por meio da avaliação e a melhoria da prática de gestão (PRÊMIO..., 2008).

0 PNQS distingue-se do Ecoblock por incluir indicadores de gestão. No entanto, o Ecoblock se propõe a enxergar toda a cadeia, enquanto que o PNQS detalha informações e aplicações específicas do setor de saneamento.

\section{A pesquisa}

A pergunta da pesquisa foi: como identificar e organizar os fatores que influenciam o desempenho ambiental de uma instituição de ensino? Os fatores, doravante denominados indicadores, foram organizados em uma estrutura de árvore: um termo superior, explicado por construtos latentes, medido por um conjunto de indicadores. A estrutura assume a forma sistêmica: subsistemas que medem partes e remontam o sistema como um todo.

A instituição estudada oferece ensino técnico e abriga três cursos superiores, dois de engenharia e um de tecnologia, totalizando mais de 3 mil alunos. Foi construída em área nativa, abriga cursos e pesquisa na área das ciências da terra e da vida e tem tradição de desenvolvimento ambiental. A instituição conta com corpo docente e pesquisadores em ciências químicas, biológicas, do ambiente, eletrônica e mecânica. Em 2002 foi formalizada a ação de um comitê ambiental, formado por professores e pesquisadores, mas que nunca fez uma avaliação formal de desempenho ambiental. Alguns membros do comitê participaram da pesquisa.

A finalidade da pesquisa é prática, ou seja, aplicar os achados na solução de problemas já identificados na realidade. 0 objetivo da pesquisa é descritivo, ou seja, inclui a descrição, observação, registro, 
análise e correlação de fatos ou fenômenos, porém sem manipulá-los (MARCONI; LAKATOS, 2007). 0 método de pesquisa foi a modelagem qualitativa: foi desenvolvido um modelo numérico que mensura opiniões de especialistas. Modelagem envolve o desenvolvimento de uma representação conceitual de um sistema, no caso, o desempenho ambiental de uma atividade antrópica, com o objetivo de organizar ideias e perspectivas e construir e verificar hipóteses sobre o objeto.

A metodologia dividiu-se em duas etapas (STRAUSS; CORBIN, 1998): uma parte qualitativa, para identificar e organizar as dimensões relevantes e os indicadores, e um levantamento numérico, para avaliar o objeto. Na parte qualitativa, o problema foi estruturado e foi formulado um modelo. Na parte numérica, o modelo foi testado em um caso.

0 método usou elementos similares aos do design-research (pesquisa-projeto) usado em produção de artefatos lógicos (HEVNER; MARCH; RAM, 2004; MANSON, 2006): após uma fase de construção mental ou teórica, surge uma ideia que deve ser verificada e refinada por estudos de caso em campo (MARCH; SMITH, 1995). Estudos de caso são apropriados para descrever e eventualmente explicar fenômenos complexos, multifacetados, sobre os quais ainda não haja suficiente teoria (BAKER, 2001; STRAUSS; CORBIN, 1998; SCHOLZ; TIETJE, 2002). Algumas vezes, um único caso, exclusivo e profundo, pode contribuir para uma teoria (DYER JUNIOR; WILKINS, 1991), desde que as informações sejam suficientemente trianguladas (EISENHARDT, 1989; JICK, 1979; EISENHARDT; GRAEBNER, 2007). Voss et al. (2002) reconhecem que os casos são aceitáveis em estudos que envolvem algum tipo de cognição e estratégia, como o deste artigo, devido à fenomenologia presente no objeto. Esse caso, juntamente com outros, em maior profundidade e amplitude, pode contribuir para um futuro modelo generalizável (EISENHARDT, 1989; STRAUSS; CORBIN, 1998) para desempenho ambiental.

\subsection{Segue o método de trabalho}

Em sessões de grupos focados com seis especialistas e pesquisadores em gestão ambiental, mediadas pelos pesquisadores, foram definidos e priorizados sete construtos latentes, ou seja, entes observáveis no ambiente, mas que não podem ser medidos diretamente, exigindo indicadores e escalas para sua apreensão. Os especialistas consultaram pesquisas anteriores e optaram pelos construtos: (i) poluição sonora, ruídos resultantes das atividades promovidas pela instituição; (ii) poluição atmosférica, gases resultantes das atividades; (iii) efluentes, resíduos líquidos resultantes das atividades; (iv) resíduos sólidos, refugos e rejeitos resultantes das atividades; (v) usos de recursos naturais e do solo necessários para as atividades; (vi) influência na vida selvagem, o quanto as atividades interferem na vida nativa da microrregião; e (vii) influência no microclima, o quanto as atividades interferem no clima da microrregião. Dos sete construtos, três apreendem impactos mais associados ao projeto das instalações (uso de recursos naturais e do solo, influência na vida selvagem e influência no microclima), e quatro às atividades antrópicas desenvolvidas na instituição (poluição sonora, poluição atmosférica, efluentes e resíduos sólidos).

Cada especialista foi convidado a ordenar os construtos segundo sua opinião quanto à gravidade da interferência no ambiente. Os julgamentos foram expressos numericamente: (mais grave $=6$; segundo mais grave $=5 ; \ldots$ menos grave $=0$ ). Cada especialista distribuiu 21 pontos entre os construtos. Como foram seis especialistas, o total distribuído foi de 126 pontos. Somaram-se e normalizaram-se os resultados, gerando um vetor de prioridades. Devido à escala adotada e ao número de respondentes, a máxima prioridade que um construto poderia assumir era de 28,5\%, evitando-se assimetrias exageradas.

A Tabela 1 mostra os resultados dessa fase.

A seguir, especialistas e pesquisadores mediaram sete grupos compostos por 20 alunos formandos do curso de engenharia de energia, com conhecimento do assunto e familiaridade com a instituição. Cada grupo definiu indicadores para apreensão de um construto latente. Dentro do construto, dividiu-se a importância de modo uniforme entre os indicadores. Em pesquisas futuras, pode-se distribuir importâncias também entre os indicadores. A seguir, os 20 alunos julgaram categoricamente os 35 indicadores segundo o grau com que, na situação atual, afetavam o ambiente e prejudicavam o construto: $($ sem dano $=4$; pouco $=3$; médio $=2 ;$ muito $=1 ;$ dano irreparável $=0$ ).

Em levantamentos do tipo survey pode-se testar os vários tipos de validade dos construtos por análise fatorial exploratória (EFA) (O'LEARY-KELLY; VOKURKA, 1998). No entanto, foram encontradas poucas correlações

Tabela 1. Construtos e priorizações.

\begin{tabular}{|c|c|c|c|c|c|c|c|}
\hline \multirow[b]{2}{*}{ Construto } & \multicolumn{6}{|c|}{ Avaliadores } & \multirow[b]{2}{*}{$\begin{array}{l}\text { Prioridade } \\
(\%)\end{array}$} \\
\hline & A1 & A2 & A3 & A4 & A5 & A6 & \\
\hline Poluição sonora & 1 & 4 & 6 & 1 & 4 & 1 & 20 \\
\hline Poluição atmosférica & 4 & 3 & 4 & 2 & 3 & 4 & 17 \\
\hline Efluentes & 3 & 1 & 1 & 6 & 1 & 2 & 22 \\
\hline Resíduos sólidos & 2 & 2 & 2 & 5 & 2 & 3 & 21 \\
\hline $\begin{array}{c}\text { Uso de recursos naturais } \\
\text { e do solo }\end{array}$ & 5 & 5 & 3 & 7 & 6 & 6 & 8 \\
\hline $\begin{array}{l}\text { Influência na vida } \\
\text { selvagem }\end{array}$ & 6 & 6 & 5 & 4 & 5 & 5 & 9 \\
\hline $\begin{array}{l}\text { Influência no } \\
\text { microclima }\end{array}$ & 7 & 7 & 7 & 3 & 7 & 7 & 3 \\
\hline
\end{tabular}


significativas entre as respostas, mesmo dentro dos construtos, o que inviabilizou a EFA. Adicionalmente, o número de respondentes é baixo. Hair et al. (2009) falam em no mínimo 100 respondentes para análise fatorial. As baixas correlações, no entanto, apontam para unidimensionalidade entre os indicadores, ou seja, pouco sombreamento entre os conteúdos, o que é desejável. Quanto à confiabilidade dos construtos, esta se baseou na teoria (CHURCHILL, 1979) que até então tem sido construída e testada sobre desempenho ambiental (SELLITTO et al., 2010, 2012).
0 resultado das avaliações é apresentado na Tabela 2. A tabela mostra a estrutura de indicadores, a média e o coeficiente de variação das 20 respostas, as avaliações por indicador, por construto e global.

$\mathrm{Na}$ primeira coluna repetem-se os construtos e sua importância relativa. Na segunda, observam-se os indicadores e sua importância, uniformemente distribuída dentro do construto. Na terceira e quarta colunas, observam-se as médias e os coeficientes de variação (cv) das 20 respostas. Os cv informam

Tabela 2. Construtos e respectivos indicadores.

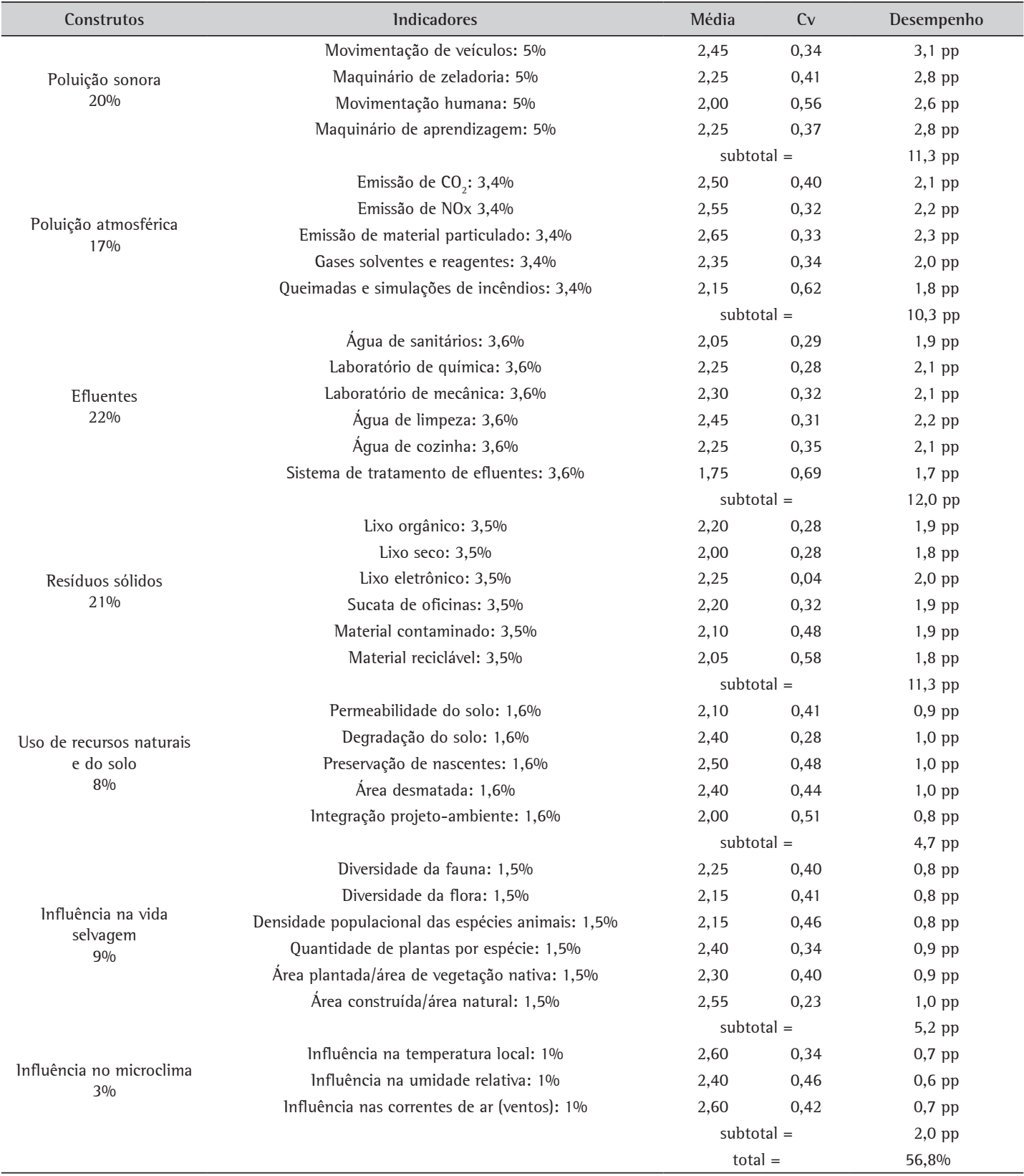


sobre o quanto os respondentes divergiram ao formar opinião sobre o indicador. Na última coluna observam-se as contribuições de cada indicador para o desempenho global, em pontos percentuais (pp). Optou-se por mensurar essa grandeza em pontos percentuais absolutos para não confundir com percentagem, que é uma proporção do máximo. Ao fim de cada bloco de linhas, observam-se os resultados parciais por construto. Na última linha, observa-se o resultado global, 56,8\%. Esse resultado informa que, de um máximo possível de 100\%, na opinião dos 20 respondentes, e segundo o modelo gerado pelos seis especialistas, a instituição cumpre $56,8 \%$ do que poderia ou deveria fazer.

Para efeito de ação estratégica, interessam as lacunas dos construtos, ou seja, a diferença entre importância (máximo desempenho possível) e desempenho. Quanto maior a lacuna, maior a responsividade do construto, ou seja, maior a probabilidade de aumentar o desempenho global para o mesmo esforço de correção. Assume-se como pressuposto que os indicadores de um mesmo construto possam ser afetados por fatores comuns. Desse modo, ações que afetem um indicador possivelmente afetarão outros no mesmo construto. Por exemplo, em Uso de recursos naturais e do solo, ações que tornem o projeto arquitetônico mais amigável ao ambiente possivelmente afetarão positivamente os demais indicadores. Nos outros construtos, pode-se esperar o mesmo em vários subconjuntos de indicadores. Secundariamente, também podem interessar os indicadores de maior dispersão na avaliação, ou seja, com maior cv.

A Tabela 3 organiza os construtos segundo as lacunas, do mais para o menos crítico.

Além da lacuna absoluta, em pp, a tabela apresenta a lacuna normalizada, ou seja, o percentual de lacuna de cada construto. Caso exista um orçamento fixo para investimento em ações ambientais, o vetor de lacunas normalizadas pode ser usado para distribuir os recursos.

Tabela 3. Responsividade dos construtos.

\begin{tabular}{ccc}
\hline Construto & Lacuna & $\begin{array}{c}\text { Lacuna normalizada } \\
(\%)\end{array}$ \\
\hline Efluentes & $10,0 \mathrm{pp}$ & 23,1 \\
Resíduos sólidos & $9,7 \mathrm{pp}$ & 22,5 \\
Poluição sonora & $8,7 \mathrm{pp}$ & 20,1 \\
Poluição atmosférica & $6,7 \mathrm{pp}$ & 15,5 \\
Influência na vida selvagem & $3,8 \mathrm{pp}$ & 8,8 \\
Usos de recursos naturais & $3,3 \mathrm{pp}$ & 7,6 \\
e do solo & $1,0 \mathrm{pp}$ & 2,3 \\
Influência no microclima & &
\end{tabular}

Fonte: Elaborada pelos autores.

\section{Discussão}

Pelo resultado final e também pela composição das parcelas, é possível discutir alternativas para melhorar o desempenho ambiental avaliado. Outra fonte de oportunidades são os indicadores de alto coeficiente de variação. Alta variabilidade nas respostas pode indicar dúvidas ou diferenças de opinião sobre a condição do indicador. Nesse caso, pode haver oportunidades de melhorias.

O construto mais crítico foi efluentes. Dos seis indicadores, dois apresentaram desempenho notavelmente inferior: sistema de tratamento de efluentes e águas sanitárias. Não existe sistema de tratamento de águas nem de esgotos, mas soluções integradas são possíveis. Projeto e instalação de ETE (estação de tratamento de efluentes) contribuiria para o desempenho ambiental, além de servir para estudos e pesquisas nos cursos técnicos e superiores mantidos pela instituição e relacionados com o tema. Os demais indicadores do construto também seriam beneficiados. Com uma ETE poderiam ser desativadas as atuais soluções parciais, menos qualificadas, mas que garantem uma avaliação razoável para efluentes dos laboratórios de química e de mecânica e das águas de limpeza e cozinha.

0 segundo construto mais crítico é resíduos sólidos. A instituição gera grandes quantidades, incluindo materiais de escritório, de laboratórios e resíduos de cozinha. Os resíduos mais impactantes são: (i) plásticos e papéis dos escritórios e salas de aula; (ii) eletrônicos provenientes dos laboratórios de eletrônica e eletrotécnica; (iii) contaminados utilizados no laboratório de química, principalmente recipientes de vidro e de plástico utilizados em amostras que não podem ser reutilizados ou inutilizados; e (iv) orgânicos gerados por alunos e principalmente pela cantina. Um programa integrado de reciclagem deve ser proposto imediatamente, se possível em parceria com as inúmeras cooperativas de recicladores da região. No passado, a instituição iniciou um programa mas este foi descontinuado. Outras instituições e universidades da região operam programas similares, com excelentes resultados, abastecendo empresas vizinhas que produzem materiais plásticos e de vidro a partir de reciclados.

0 próximo construto foi poluição sonora. Quanto ao ruído originado por veículos, já existe um plano de controle. É proibida a entrada de ônibus, carros e motos de estudantes e visitantes no pátio interno da instituição. São autorizadas entradas apenas para professores e funcionários, que representam trânsito de pequena monta e concentrado nos horários de entrada e saída de turnos, o que deixa o nível de ruído aceitável e não perturba as atividades escolares. 
Nos outros três indicadores, medidas são necessárias. Quanto aos ruídos humanos, devem ser destinadas áreas e horários exclusivos para lazer e recreação e proibidos eventos e encontros sociais e culturais nas proximidades de salas de aula. São práticas usuais na instituição concursos musicais, olimpíadas estudantis e manifestações culturais de estudantes secundaristas em horário de aula e próximo às salas destinadas aos cursos de engenharia, inviabilizando atividades acadêmicas em várias semanas do ano. Por fim, os indicadores referentes a maquinário de conservação e zeladoria (compressores, roçadeiras, cortadores de grama) e de aprendizagem podem ser tratados em conjunto, pois as medidas tomadas são similares. Em ambos os casos, os ruídos são gerados pela falta de manutenção nos equipamentos e por defasagens tecnológicas. São necessárias reformas e eventuais substituições.

Segue poluição atmosférica. Observam-se baixas emissões de $\mathrm{CO}_{2}$ e NOx. Mesmo sabendo que os gases formadores do efeito estufa são seis (os outros são $\mathrm{CH}_{4}, \mathrm{SF}_{6}$, PFC e HFC) (WILLARD, 2005), os especialistas entenderam que apenas esses dois são gerados significativamente na instituição. Material particulado e gases solventes também foram bem avaliados. Em parte, a baixa emissão é devida à restrição de trânsito de veículos e ao uso de frações pequenas e controladas nos laboratórios. Dentre os indicadores do construto, o mais mal avaliado foi o das queimadas. Essas são praticadas eventualmente na área da instituição e quando da simulações de incêndio em aulas práticas dos cursos de segurança do trabalho. Tais práticas podem e devem ser minimizadas ou abolidas pela instituição.

0 construto influência na vida selvagem tem menor importância, o que torna menos urgentes possíveis melhorias. Ainda assim, alguns indicadores não tiveram avaliações satisfatórias e em algum momento deverão ser enfocados. Os indicadores mais mal avaliados foram diversidade da flora e densidade populacional das espécies animais. Ambos podem ser melhorados por planos de revitalização de espécies.

Segue o uso de recursos naturais e do solo. Nesse construto foi avaliada a relação entre o projeto arquitetônico e o meio ambiente. Um dos principais aspectos avaliados foi o quanto as instalações obstruíram, impermeabilizaram e desgastaram o solo. Foram avaliadas a permeabilidade e a degradação do solo; a manutenção das nascentes; a área original que foi desmatada; e a integração do ambiente natural ao projeto arquitetônico. Quanto a essa última, não existia no projeto arquitetônico inicial um plano para minimizar o uso dos recursos naturais e do solo. Contudo, o desempenho dos indicadores foi satisfatório, principalmente quanto às nascentes, degradação e área desmatada, pois no complexo educacional não há atividades que degradem o solo e existe esforço da instituição para manter a vegetação. Os indicadores permeabilidade do solo e integração do ambiente natural ao projeto arquitetônico apresentaram resultados menos satisfatórios, pois as instalações interagem mal com o meio. 0 projeto pode e deve ser atualizado, dessa vez sob uma perspectiva ambientalmente mais amigável.

Por fim, o construto influência no microclima também tem pequena importância. Como a atividade educacional (se comparada à industrial) tem pequeno impacto térmico e energético, exige muito pouca matéria-prima e devolve muito pouco material e energia ao ambiente, a influência no microclima é pequena. É possível aumentar o desempenho médio, mas esse construto tem menos prioridade.

Quanto ao método, observaram-se algumas particularidades: (i) houve interesse e comprometimento de especialistas (professores pesquisadores), com conhecimento científico e empírico sobre o caso, pois exercem atividade profissional na instituição; (ii) houve transparência e objetividade na comunicação dos resultados, pois o modelo fornece desempenho global e detalhado por indicadores e construtos e a contribuição de cada parcela para o resultado global; (iii) houve sensível redução de custos em relação a outros métodos, pois surgiram resultados em curto espaço de tempo, sem instrumentação de campo, o que fez com que o comitê da instituição avaliasse a possibilidade de adotar em definitivo o método para avaliação periódica de desempenho ambiental; (iv) houve valorização da percepção e da subjetividade humana, muito mais multifacetada do que indicadores medidos por grandezas físicas de campo, o que incluiu desperdícios de matéria-prima, estruturas funcionais inadequadas, comportamento humano, equipamentos obsoletos, entre outras precariedades, que talvez não fossem percebidas por medições objetivas por instrumentação; (v) resultou um plano de melhorias, cujo objetivo é elevar rapidamente o desempenho ambiental global da instituição; e (vi) apesar de discutidos outros métodos, os especialistas preferiram mensurar apenas indicadores operacionais, negligenciando indicadores gerenciais, pois a instituição não opera um SGA formal.

Sintetizando, as ações de melhoria foram organizadas em blocos de atividade: (i) maquinário: manutenção de rolamentos, partes móveis e isolamento acústico de casas de máquinas; (ii) comportamento humano: construção de áreas de convivência afastadas para redução de ruídos nos corredores e arredores das salas de aula, de estudo e da biblioteca; (iii) oficina de usinagem: manutenção do maquinário e isolamento acústico das instalações; (iv) proibição de práticas de 
queimadas e simulações de incêndio; (v) efluentes sanitários, do laboratório de química, cozinha e sistema de tratamento de efluentes: implantação de sistemas de tratamento de efluentes; (vi) lixo orgânico: reaproveitamento e destinação para compostagem; (vii) lixo seco, sucata, lixo eletrônico e programas de reciclagem: formação de centro de reciclagem de material gerado na instituição e também trazido pela comunidade, tal como em outras universidades da região; e (viii) material contaminado: encaminhar para o centro de reciclagem especial da instituição, ligado aos cursos de química e biologia.

Concluindo a discussão, salientam-se indicadores de maior coeficiente de variação (cv), o que pode indicar diferença de percepção sobre o indicador ou baixa confiabilidade nas respostas, causada por mau entendimento. Como foram coletadas opiniões sobre indicadores objetivos (situação de $\mathrm{CO}_{2}$ ou NOx, estado de preservação das nascentes etc.), que podem ser mensurados objetivamente por grandezas físicas de campo, eventual falta de confiabilidade não pareceu ter sido relevante. Não pareceu que respondentes não tivessem certeza sobre o que responderam. Portanto, assumiu-se o pressuposto de que indicadores com alto c $v$ apresentaram maior dificuldade ou subjetividade na avaliação. Essa é uma implicação de avaliações qualitativas. Portanto, mesmo com médias altas é possível que existam fatores de risco nas avaliações, o que recomendaria atenção ao indicador.

Os indicadores de maior dispersão foram: (i) movimentação humana (média $=2$; $\mathrm{cv}=0,56$ ); (ii) queimadas e simulações de incêndio (média $=2,15$; $\mathrm{cV}=0,56$ ); (iii) sistema de tratamento de efluentes (média $=1,75 ; \mathrm{cv}=0,69$ ); e (iv) material reciclável (média $=2,05 ; \mathrm{cv}=0,58$ ). Nesse caso particular todos os indicadores de elevado cv também tiveram baixa média, portanto suas implicações já foram tratadas. A elevada dispersão nas opiniões reforça a necessidade de propor planos de ação para esses indicadores.

\section{Considerações finais}

0 objetivo deste artigo foi avaliar o desempenho ambiental de uma instituição educacional que abriga cursos técnicos e de engenharia. A instituição acolhe mais de 3 mil alunos e foi construída em extensa área nativa, com tradição de ensino e pesquisa de ciências, inclusive da terra e ambiental. 0 principal método de pesquisa foi a modelagem qualitativa. 0 método de trabalho utilizado baseou-se em adaptação do método SBP. Ao final, o desempenho ambiental da instituição atingiu 56,8\%. Por se tratar de instituição de ensino e pesquisa, esse desempenho pode ser considerado apenas intermediário. Existe uma lacuna de 43,2\% que pode ser trabalhada por professores pesquisadores e alunos e que assim, além de melhorar o resultado ambiental, pode agregar inovações para os cursos.

0 método apontou que é possível aumentar o desempenho, centralizando esforços nos poucos indicadores que apresentaram resultados médios mais baixos e dispersões de opinião mais altas. Pode-se assumir o pressuposto que, com esforços similares, a pontuação final subirá mais se as ações forem concentradas nos indicadores priorizados. 0 processo de avaliação permite a elaboração de uma política ambiental e exige reavaliação periódica dos resultados das ações. Eventualmente, o método pode sugerir reformulações na estratégia ambiental, caso as ações se mostrem ineficientes após sucessivas rodadas de avaliações.

Para que a instituição melhore seu desempenho ambiental e se compatibilize com o desenvolvimento sustentável, é importante o comprometimento da direção, professores, alunos e funcionários para consolidar esse processo proposto de avaliação e constante melhoria. A pesquisa apontou que não são necessários grandes investimentos e, principalmente, que o resultado obtido poderia ter sido melhor, pois existem elementos materiais e recursos humanos suficientes para propor projetos socioambientais compatíveis com a nova realidade ambiental do século XXI.

Como continuidade de pesquisa, sugere-se reaplicar o método na própria instituição, distribuindo importâncias relativas também entre os indicadores e comparando resultados. Caso a diferença seja pequena, talvez seja vantajoso manter uniforme a distribuição de importância dentro dos construtos. Também sugere-se a replicação periódica da avaliação e a formação de uma série histórica de resultados.

\section{Agradecimentos}

Agradece-se à instituição, alunos e pesquisadores que participaram da pesquisa, parcialmente financiada pelo CNPq.

\section{Referências}

ADLMAIER, D.; SELLITTO, M. Embalagens retornáveis para transporte de bens manufaturados: um estudo de caso em logística reversa. Produção, v. 17, n. 3, p. 395-406, 2007.

GRAEL, P.; OLIVEIRA, O. Sistemas certificáveis de gestão ambiental e da qualidade: práticas para integração em empresas do setor moveleiro. Produção, v. 20, n. 1, p. 30-41, 2010. http://dx.doi.org/10.1590/ S0103-65132010005000017

ASSOCIAÇÃO BRASILEIRA DE NORMAS TÉCNICAS - ABNT. NBR ISO 14004: Sistemas de gestão ambiental: diretrizes gerais sobre princípios, sistemas e técnicas de apoio. Rio de Janeiro: ABNT, 1996. 
ARAUJO, P.; MACHADO, M. 0 novo estatuto do meio ambiente na prática empresarial mundializada: uma análise preliminar sobre a logística reversa. Gaia Scientia, v. 1, n. 1, p. 67-75, 2007.

ÁVILA, G.; PAIVA, E. Processos operacionais e resultados de empresas brasileiras após a certificação ambiental ISO 14001. Gestão \& Produção, v. 13, n. 3, p. 475487, 2006.

BARATA, M.; KLIGERMAN, D.; MINAYO-GOMEZ, C. A gestão ambiental no setor público: uma questão de relevância social e econômica. Ciência \& Saúde Coletiva, v. 12, n. 1, p. 165-170, 2007. http://dx.doi.org/10.1590/S141381232007000100019

BARBIERI, J. Gestão ambiental empresarial: conceitos, modelos e instrumentos. São Paulo, Saraiva, 2004.

BAKER, M. Selecting a research methodology. The Marketing Review, v. 1, n. 3, p. 373-397, 2001. http://dx.doi. org/10.1362/1469347002530736

BORGES, A.; ROSA, F.; ENNSLIN, S. Evidenciação voluntária das práticas ambientais: um estudo nas grandes empresas brasileiras de papel e celulose. Produção, v. 20 , n. 3, p. 404-417, 2010. http://dx.doi.org/10.1590/ S0103-65132010005000034

BRUNDTLAND, G. Our common future. Oxford: The World Commission on Environment and Development, Oxford University Press, 1987.

CAMPOS, L.; MELO, D. Indicadores de desempenho dos Sistemas de Gestão Ambiental (SGA): uma pesquisa teórica. Produção, v. 18, n. 3, p. 540-555, 2008.

CHEHEBE, J. Análise do Ciclo de Vida de Produtos - Ferramenta Gerencial da $1 \mathrm{SO}$ 14000. Rio de Janeiro: Qualitymark, 1997.

CHURCHILL, G. A paradigm for developing better measures of marketing constructs. Journal of Marketing Research, v. 16, n. 1, p. 64-73, 1979. http://dx.doi. org/10.2307/3150876

DONAIRE, D. Gestão Ambiental na Empresa. São Paulo: Atlas, 1999.

DONNELLY, K. et al. ISO 14001 - effective management of sustainable design. The Journal of Sustainable Product Design, v. 4, n. 2, p. 43-54, 2004. http://dx.doi. org/10.1007/s10970-006-0004-9

DYER JUNIOR, G.; WILKINS, A. Better stories, no better constructs, to generate better theory: a rejoiner to Eisenhardt. Academy of Management Review, v. 16, n. 3, p. 613-619, 1991.

EPELBAUM, M. A influência da Gestão Ambiental na Competitividade e no Sucesso Empresarial. 2004. Dissertação (Mestrado em Engenharia de Produção)Universidade de São Paulo, São Paulo, 2004.

EISENHARDT, K. Building theories from case study research. Academy of Management Review, v. 14, n. 4, p. 532550, 1989.

EISENHARDT, K.; GRAEBNER, M. Theory building from cases: opportunities and challanges. Academy of Management Journal, v. 50, n. 1, p. 25-32, 2007. http://dx.doi. org/10.5465/AMJ.2007.24160888

HAIR, J. et al. Multivariate Data Analysis. Upper Saddle River: Prentice Hall, 2009.

HEVNER, A.; MARCH, S.; RAM, S. Design Science in Information Systems Research. Management Information System Quarterly, v. 28, n. 1, p. 75-106, 2004.

KRAJNC, D.; GLAVIC, P. How to compare companies on relevant dimensions of sustainability. Ecological Economics, v. 55, n. 4, p. 551-563, 2005. http://dx.doi. org/10.1016/j.ecolecon.2004.12.011
KUEHR, R. Environmental technologies: from a misleading interpretations to an operational categorization and definition. Journal of Cleaner Production, v. 15, n. 13-14, p. 1316-1320, 2007. http://dx.doi.org/10.1016/j. jclepro.2006.07.015

KUHRE, W. ISO 14031 - Environmental performance evaluation (EPE): practical tools techniques for conducting an environmental performance evaluation. Upper Saddle River: Prentice Hall, 1998.

JICK, T. Mixing qualitative and quantitative methods: triangulation in action. Administrative Science Quarterly, v. 24, n. 4, p. 602-611, 1979. http://dx.doi. $\operatorname{org} / 10.2307 / 2392366$

JOHNSON, S. Identification and selection of environmental performance indicators: application of the balanced scorecard approach. Corporate Environmental Strategy, v. 5, n. 4, p. 34-41, 1998. http://dx.doi.org/10.1016/ S1066-7938(00)80079-2

MANSON, N. 1s Operations Research Really Research? Journal of Operations Research Society of South African, v. 22, n. 2, p. 155-180, 2006.

MARCH, S.; SMITH, G. Design and Natural Science Research on Information Technology. Decision Suport System, v. 3, n. 3, p. 251-266, 1995. http://dx.doi. org/10.1016/0167-9236(94)00041-2

MARCONI, M.; LAKATOS, E. Técnicas de Pesquisa. São Paulo: Atlas, 2007.

MATIAS, H.; PINHEIRO, J. Desenvolvimento sustentável: um discurso sobre a relação entre desenvolvimento e natureza. Psicologia Social, v. 20, n. 1, p. 134-143, 2008. http://dx.doi.org/10.1590/S0102-71822008000100015

MATTHEWS, D. Environmental management systems for internal corporate environmental benchmarking. Benchmarking: An International Journal, v. 10, n. 2, p. 95-106, 2003.

MELO, J.; PEGADO, C. Ecoblock: A method for integrated environmental performance evaluation of companies and products (construction case-study). In: INTERNATIONAL CONFERENCE ON ECOBALANCE, 5., 2002, Tsukuba. Proceedings... Tsukuba: The Society of Non-traditional Technology, 2002.

MICHELSEN, O.; MAGERHOLM, A.; DAHLSRUD, A. Eco-efficiency in extended supply chains: A case study of furniture production. Journal of Environmental Management, v. 79, n. 3, p. 290-297, 2006. PMid:16253417. http://dx.doi.org/10.1016/j. jenvman.2005.07.007

MOTTA, R. Desafios ambientais da economia brasileira. Rio de Janeiro: IPEA - Instituto de Pesquisa Econômica Aplicada, 1997. Texto para discussão, n. 509.

MOTTA, R. Indicadores ambientais no Brasil: aspectos ecológicos, de eficiência e distributivos. Rio de Janeiro: IPEA - Instituto de Pesquisa Econômica Aplicada, 1996. Texto para discussão, n. 509.

O'LEARY-KELLY, S.; VOKURKA, R. The empirical assessment of construct validity. Journal of Operations Management, v. 16, n. 4, p. 387-405, 1998. http://dx.doi.org/10.1016/ S0272-6963(98)00020-5

OLIVEIRA, 0.; PINHEIRO, C. Implantação de sistemas de gestão ambiental ISO 14001: uma contribuição da área de gestão de pessoas. Gestão \& Produção, v. 17, n. 1, p. 51-61, 2010. http://dx.doi.org/10.1590/S0104530X2010000100005

ORGANIZAÇÃO DAS NAÇÕES UNIDAS - ONU. Disponível em $<$ http://www.onu-brasil.org.br/>. Acesso em: 15 ago. 2010. 
OTTMAN, J. Marketing Verde: desafios e oportunidades para a nova era do marketing. São Paulo, Makron Books, 1994.

PEGADO, C.; MELO J.; RAMOS, T. Ecoblock: método de avaliação do desempenho ambiental. In: CONGRESSO NACIONAL DE ENGENHEIROS DO AMBIENTE, 2001, Lisboa. Anais... Lisboa: APEA, 2001.

PIMENTA, H.; GOUVINHAS, R. Implementação da produção mais limpa na indústria de panificação de Natal-RN. In: ENCONTRO NACIONAL DE ENGENHARIA DE PRODUÇÃO - ENEGEP, 27., 2007, Foz do lguaçu. Anais... Foz do lguaçu: ABEPRO, 2007.

PRÊMIO NACIONAL DE QUALIDADE EM SANEAMENTO - PNQS. Guia PNQS 2008. Disponível em: <www.pnqs.com.br> Acesso em: 20 set. 2010.

REIS, M. ISO 14.000 - Gerenciamento Ambiental: um novo desafio para sua competitividade. Rio de Janeiro: Qualitymark, 1995.

ROWLAND-JONES, R.; PRYDE, M.; CRESSER, M. An evolution of current environmental management systems as indicators of environmental performance. Management of Environmental Quality, v. 16, n. 3, p. 211-219, 2005. http://dx.doi.org/10.1108/14777830510591642

SCHOLZ, R.; TIETJE, 0. Embedded case study methods: Integrating quantitative and qualitative knowledge. Thousand Oaks: Sage Publications, 2002.

SEIFFERT, M. ISO 14001 Sistemas de Gestão Ambiental: Implantação Objetiva e Econômica. São Paulo: Atlas, 2007.

SOUZA, M.; SILVA, R. A geração de resíduos industriais e sua destinação final. In: ENCONTRO NACIONAL DE ENGENHARIA DE PRODUÇÃO - ENEGEP, 1997, Gramado. Anais... Gramado: ABEPRO, 1997.

SELLITTO, M.; BORCHARDT, M.; PEREIRA, G. Avaliação de desempenho ambiental em duas operações de manufatura. In: ENCONTRO NACIONAL DE ENGENHARIA DE PRODUÇÃO - ENEGEP, 28., 2008, Rio de Janeiro. Anais... Rio de Janeiro: ABEPRO, 2008.

SELliTTO, M.; BORCHARDT, M.; PEREIRA, G. Avaliação de desempenho ambiental em duas operações de fabricação de pequeno porte. In: SIMPÓSIO DE ENGENHARIA DE PRODUÇÃO - SIMPEP, 16., 2009, Bauru. Anais... Bauru: UNESP, 2009.

SELLITTO, M.; BORCHARDT, M.; PEREIRA, G. Modelagem para avaliação de desempenho ambiental em operações de manufatura. Gestão \&t Produção, v. 17, n. 1, p. 95-109, 2010. http://dx.doi.org/10.1590/ S0104-530X2010000100008

SELLITTO, M. et al. Environmental performance assessment in two logistic operations: transportation and warehousing. In: INTERNATIONAL CONFERENCE ON INDUSTRIAL ENGINEERING AND OPERATIONS MANAGEMENT - ICIEOM, 16., 2010, São Carlos. Proceedings... São Carlos: ABEPRO, 2010.

SELLITTO, M. et al. Environmental performance assessment of a provider of logistical services in an industrial supply chain. Theoretical Foundations of Chemical Engineering, v. 46, n. 6, p. 691-703, 2012.

STRAUSS, A.; CORBIN, J. Basics of qualitative research: Techniques and procedures for developing grounded theory. Thousand Oaks: Sage, 1998.

VAllE, C. Qualidade Ambiental: como ser competitivo protegendo o meio ambiente. São Paulo: Pioneira, 1995.

VALLE, C. Qualidade ambiental: ISO 14000. São Paulo: SENAC, 2002.

VERDUM, V.; SELLITTO, M. Avaliação de desempenho energético em uma instituição de ensino. Revista Liberato, v. 10, n. 13, p. 15-33, 2009.

VOSS, C.; TSIKRIKTSIS, N.; FROHLICH, M. T. Case research in operations management. International Journal of Operations \& Production Management. v. 20, n. 2, p. 196-219, 2002.

WAAGE, S. Re-considering product design: a practical road map for integration of sustainability issues. Journal of Cleaner Production, v. 15, p. 638-649, 2007. http:// dx.doi.org/10.1016/j.jclepro.2005.11.026

WALKER, H.; DI SISTO, L.; McBAIN, D. Drivers and barriers to environmental supply chain management practices: lessons from the public and private sectors. Journal of Purchasing and Supply Management, v. 14, n. 1, p. 69-85, 2008. http://dx.doi.org/10.1016/j. pursup.2008.01.007

WILLARD, B. The perfect storm of sustainability mega-issues: threat or opportunity for business? In: KAHRE, A. (Org.). Emerging dimensions of environmental sustainability. Berlin: Fachbuch Verlag Winkler, 2005.

ZOBEL, T. et al. Identification and assessment of environmental aspects in an EMS context: an approach to a new reproducible method based on LCA methodology. Journal of Cleaner Production, v. 10, n. 4, p. 381-396, 2002. http://dx.doi.org/10.1016/S09596526(01)00054-3

\title{
Environmental performance assessment of a public institution of technical and undergraduate education
}

\begin{abstract}
This article reports a case study in which the environmental performance of a public institution of higher and technical education was evaluated, based on environmental indicators in spades. The following standards series were reviewed: 150 14000, National Quality Award in Sanitation (PNQS) and Ecoblock. The method was adapted from $S B P$, a set of procedures for measuring the environmental performance of an anthropic activity, composed by latent constructs and categorical indicators that explain the performance. The indicators were organized in seven constructs. According to the assessed respondents and the model, the institution reached $56.7 \%$ of the maximum possible in environmental management. Lower constructs were management of solid waste and noise pollution. The evaluation can be used for reshaping the environmental policy of the institution.
\end{abstract}

\section{Keywords}

Environmental performance. Assessment methods. Environmental indicators. 